\title{
Study of the structural and photoluminescence properties of CdTe polycrystalline films deposited by close-spaced vacuum sublimation
}

\author{
V. Kosyak ${ }^{\mathrm{a}, *}$, A. Opanasyuk ${ }^{\mathrm{b}}$, P.M. Bukivskij ${ }^{\mathrm{c}}$, Yu.P. Gnatenko ${ }^{\mathrm{c}}$ \\ a Sumy State University, Department of Electroenergetics, Rimsky-Korsakov Str. 2, UA-40007 Sumy, Ukraine \\ b Sumy State University, Department of Applied Physics, Rimsky-Korsakov Str. 2, UA-40007 Sumy, Ukraine \\ ${ }^{\mathrm{c}}$ Institute of Physics of NAS of Ukraine, Prospect Nauky 46, 680028 Kyiv, Ukraine
}

Keywords:

A1. Crystal structure

A1. X-ray diffraction

A1. Defects

A3. Polycrystalline deposition

B1. Cadmium compounds

\begin{abstract}
A B S T R A C T
The polycrystalline CdTe films were deposited by the close-spaced vacuum evaporation at the different substrate temperatures $\left(150-550{ }^{\circ} \mathrm{C}\right)$. The X-ray diffraction measurements of structural and substructural properties of these films were carried out to study their phase composition and texture. The films' parameters such as the coherent scattering domain size, microdeformation level and mean density of dislocations were determined based on the broadening of diffraction peaks. In this case the Hall and three-fold convolution approximations were used. Surface morphology, grain size and growth mechanism of the films were determined by the scanning electron microscopy. The low temperature photoluminescence measurements allowed us to establish the correlation between the point and extended defect structure on the one hand and the growth conditions on the other. As a result, the growth conditions of CdTe polycrystalline films with fairly good crystal and optical quality were determined.
\end{abstract}

\section{Introduction}

At present the development of high-performance and low-cost solar cells for production of nonconventional energy sources based on the photovoltaic effect is an urgent scientific and technological problem [1]. The CdTe polycrystalline films as an adsorber layer are one of the most promising candidates for largescale photovoltaic energy conversion. This is due to the nearoptimum band gap and high optical absorption of CdTe. Therefore, more than $90 \%$ of the incident light is absorbed in a few micrometers of the material. In this case, it is possible to fabricate a complete photovoltaic device using only thin film technology. Up to date high efficiency (16.5\%) of CdTe-based solar cells have been achieved [2,3]. However, the theoretical estimations of possible photovoltaic solar energy conversion into electricity for CdTe are of about 28\% [4].

It should be noted that the CdTe films have some specific structural and substructural peculiarities, namely: coexisting of two polymorphous modifications of material (sphalerite and wurtzite), high concentration of twins, stacking faults (SF) defects, dislocation and high level of microdeformation [5,6]. Besides, the extended and point defects in CdTe are the electrically active states [7]. Therefore, they have strong effect on the optical and photoelectric properties of thin films and thus considerably determine solar cells efficiency [8,9]. Further increase in the efficiency of CdTe-based solar cells can be reached only if the structurally perfect CdTe films with optimal defect structure will be used.

It should be noted that the study of the structural properties of CdTe films were widely carried out in $[5,6,8,9]$, but the substructure properties are significantly less studied $[5,10]$.

The low temperature photoluminescence measurements are very effective method of investigation of the defect structure in the various semiconductor materials including the polycrystalline thin films [11-16]. It allows to determine the nature and energy levels of the point defects as well as the concentration of dislocations in the films. However, influence of substructural peculiarity of CdTe polycrystalline films on photoluminescence properties is not studied.

A variety of techniques such as thermal evaporation, metal organic chemical vapor deposition, sputtering, molecular beam deposition, close-spaced sublimation (CSS), etc. were used for CdTe films deposition $[1,17]$. The CSS method allows to grow the high-quality, low-cost semiconductor thin films using the growth condition close to the thermodynamic equilibrium at rough vacuum. Therefore, CSS method is widely used for the deposition of CdTe films [1,8,9,17,18]. This technique has many variants [1]: sublimation of compound with the inert carrier gas $\left(\mathrm{Ar}, \mathrm{N}_{2}\right)$ $[13,14]$, vacuum sublimation with [8] or without hot-walls $[9,17,19]$.

The main objective of the paper is study of the structural, substructural and photoluminescence properties of $\mathrm{CdTe}$ 
polycrystalline films deposited by close-spaced vacuum sublimation (CSVS) in order to determine optimal growth conditions of the CdTe films with good structural and optical quality.

\section{Experimental procedure}

The scheme of the device for the deposition of CdTe polycrystalline films using the CSVS method $[1,8,17,20]$ is shown in Fig. 1. The stoichiometric powder of CdTe (99.999\%) was evaporated in an evaporator (1) with a molybdenum boat (2). In order to prevent vapor condensation the walls (4) were heated by the wall electric heater (3). The vapor transport occurred in the cylindrical enclosed volume (5) at the temperature gradient between the evaporator and substrate (8). The substrate holder (6) with substrate electric heater (7) was pressed near the enclosed volume. The substrate was fixed at a distance of about $17 \mathrm{~mm}$ from the evaporator. Temperature control was performed by the thermocouples (9). The CSVS device was equipped with thermo-shield (10) and was placed in vacuum chamber with the vacuum level of $10^{-4} \mathrm{~Pa}$.

The CdTe polycrystalline films were deposited for $7 \mathrm{~min}$ on the glass substrates at different growth conditions, namely: the evaporator temperature $\left(T_{e}\right)$ was $620^{\circ} \mathrm{C}$, the substrate temperature $\left(T_{S}\right)$ varied from 150 to $550{ }^{\circ} \mathrm{C}$ and the wall temperature $T_{w}=650^{\circ} \mathrm{C}$

Surface morphology was investigated by a scanning electron microscopy (SEM). Average grain size $(d)$ in the layers of the film was estimated by the Jeffries method. Thickness of the films $(l)$ was measured by the SEM using the results of the cross-section of samples. Structural investigations of the films were performed with an X-ray diffractometer DRON 4-07 in the range of diffraction angles $20^{\circ} \leq 2 \theta \leq 60^{\circ}$ (where $2 \theta$ is the Bragg angle) using a Ni-filtered $\mathrm{K}_{\alpha} \mathrm{Cu}$ radiation source. Phase analysis was carried out by comparisons of the interplane distances and relative intensities of the investigated and reference samples in accordance with the JCPDS standard [21].

The texture of the films was estimated by the Harris method $[22,23]$. The pole density was calculated as $C_{i}=\left(I_{i} / I_{0 i}\right) /$ $(1 / N) \sum_{i=1}^{N}\left(I_{i} / I_{0 i}\right)$, where $N$ is the number of lines observed in the diffraction patterns, $I_{0}, I_{0 i}$, are the integral intensities of

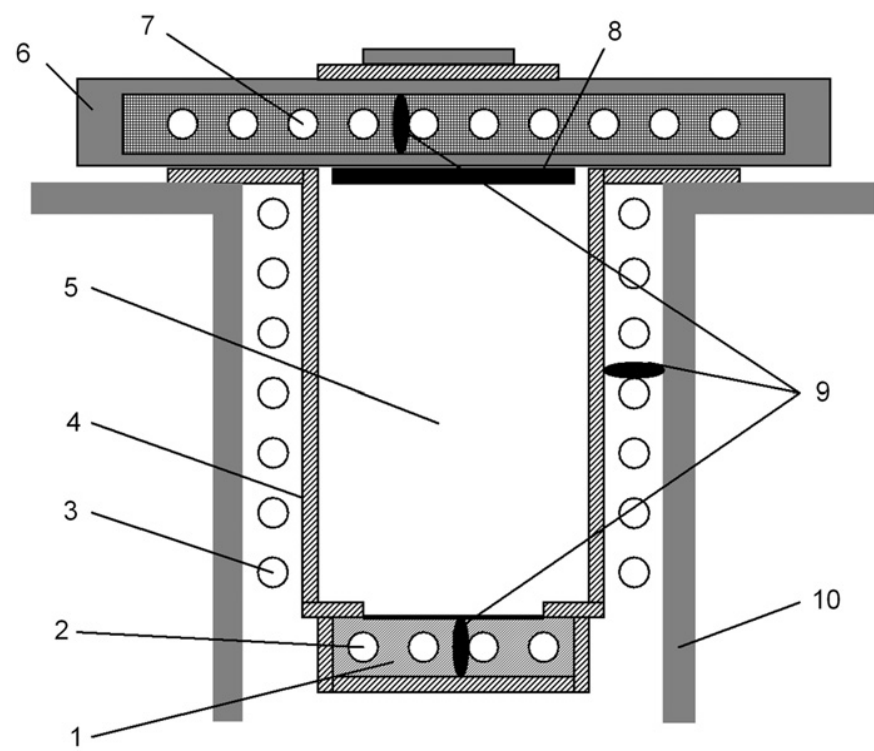

Fig. 1. Scheme of CSVS device: 1-evaporator, 2-molybdenum boat, 3-walls heater, 4-walls, 5-enclosed volume, 6-substrate holder, 7-substrate heater, 8-substrate, 9-thermocouples, 10-thermo-shield. $i$-diffraction peak for the film and reference sample, respectively. The orientation factor was found using the following equation: $f=\sqrt{(1 / N) \sum_{i=1}^{N}\left(C_{i}-1\right)^{2}}$. CdTe powder was used as a nontextured reference.

X-ray method was also applied for determination of the coherent scattering domain (CSD) size $(L)$ and microdeformation level $(\varepsilon)$ in CdTe films according to the broadening of the diffraction peaks $[22,23]$. Cauchy and Gauss approximations were used to separate diffraction broadening due to the physical effects and tool broadening. In order to separate the contributions in physical broadening from the dispersive structure of the polycrystalline films and microdeformation the Hall approximation was applied. This allowed to calculate the values of $L$ and $\varepsilon$ with accuracy of about $30-50 \%[22,23]$. In order to provide more precise calculations of $L$ and $\varepsilon$ values with the accuracy of about $11-16 \%$ the three-fold convolution method was used [24,25].

It is well known, that the CSD are formed by the dislocations situated on the domain boundary. In addition, the dislocation can be situated in the domain volume. Evaluation of the average density of such dislocations $\left(\rho_{V}\right)$ as well as the total concentration of dislocations $\left(\rho_{T}\right)$ were carried out using the $\varepsilon$ and $L$ values $[26,27]$. Besides, the concentration of SF $(\alpha)$ in the films was calculated by the method described in $[25,26]$.

The photoluminescence spectra were measured using an SDL-1 grating spectrometer [11,12]. An LGN-404 argon laser was used for excitation by the $514 \mathrm{~nm}$ line, together with an FEU-62 photomultiplier in the photon-counting mode. The excitation intensity was kept below $1.0 \mathrm{~W} / \mathrm{cm}^{2}$ to avoid the sample heating. The samples were mounted on the cold finger of a variable temperature liquid-helium cryostat. The accuracy of the measurements and temperature stabilization by the UTREKS system was $0.01 \mathrm{~K}$. The exciting beam was modulated by a mechanical chopper and the luminescence signal was measured using a phase-sensitive lock-in detection system. The spectral resolution of the system was of the order of $1 \mathrm{~cm}^{-1}$.

\section{Results and discussion}

The thicknesses of the films are $l \approx 18 \mu \mathrm{m}$ for the samples obtained at $T_{s} \leq 350{ }^{\circ} \mathrm{C}$ and decrease to $l \approx 14 \mu \mathrm{m}$, due to the reevaporation of compound at high substrate temperature, for the samples deposited at high temperature $T_{s} \geq 450{ }^{\circ} \mathrm{C}$ (Fig. 2).

SEM investigation shows that the films obtained at $T_{s} \leq 200{ }^{\circ} \mathrm{C}$ (Fig. 2 a, b) have a highly dispersed structure with the average grain size about $d \leq 1 \mu \mathrm{m}$. The orientation of crystallites is uniaxial. Further increase of the substrate temperature leads to the increase of grain size up to $d=4 \mu \mathrm{m}$ at $T_{s}=350{ }^{\circ} \mathrm{C}$ (Fig. $2 \mathrm{c}$, d). Moreover, the change of the thin film growth mechanism obtained at $T_{s}>350{ }^{\circ} \mathrm{C}$ occurred. In this case, the films have a columnar-like structure with clear growth texture (Fig. 2 e, f). The diameter of columnar-like crystallites strongly depends on the growth conditions $\left(T_{s}, T_{e}, \Delta T=T_{e}-T_{s}\right)$. It can be explained by the rapid decrease of the vapor supersaturation during the film growth for small value of $\Delta T$. The columnar-like structure was most pronounced in the films obtained at the growth conditions near the thermodynamic equilibrium $\left(T_{s}=500-550^{\circ} \mathrm{C}\right.$, $\left.\Delta T<150{ }^{\circ} \mathrm{C}\right)$. In this case, the films have practically a monoblock structure along the layers thickness and the grain size is about of $13 \mu \mathrm{m}$ (Fig. 2 e, f).

X-ray patterns of the CdTe films deposited at the different growth conditions are presented in Fig. 3a. Normalization of peak intensity was performed according to the $\left(\begin{array}{lll}1 & 1 & 1\end{array}\right)$ reflection peak intensity which correspond to the cubic phase. X-ray patterns 

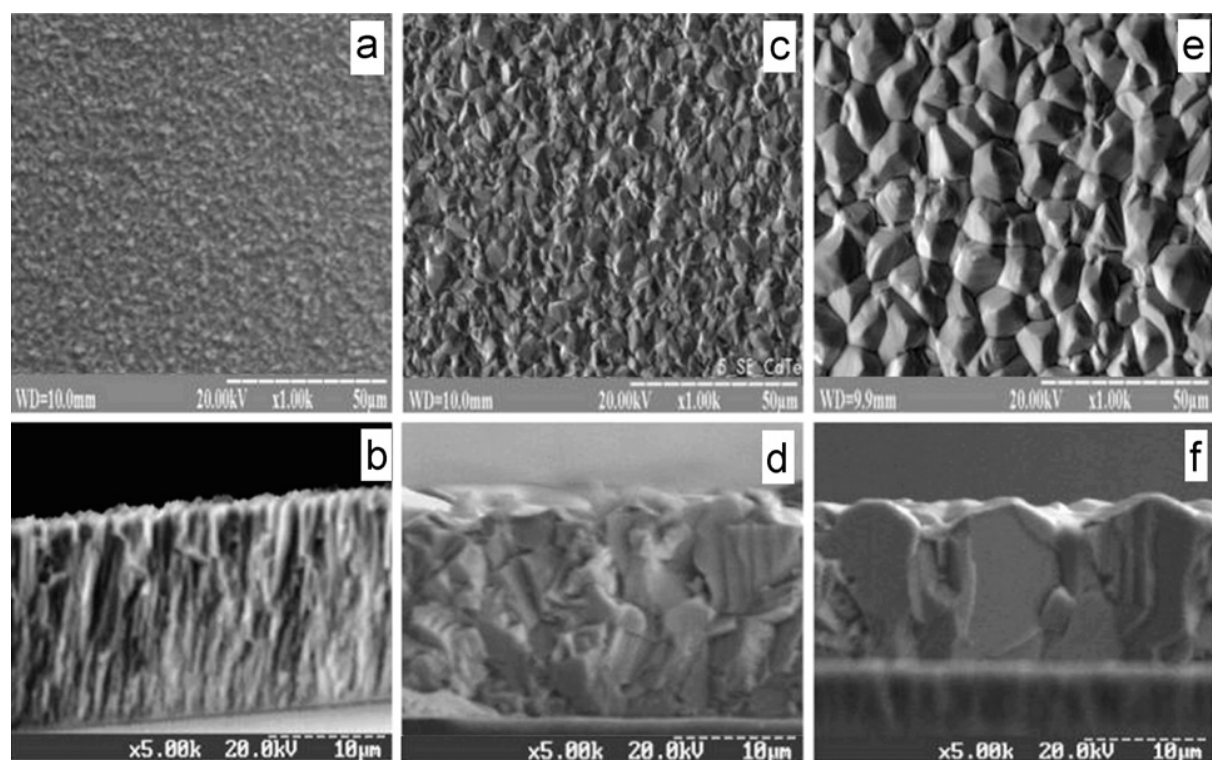

Fig. 2. SEM images of surface and cross-section of $\mathrm{CdTe}$ films obtained at $T_{e}=620{ }^{\circ} \mathrm{C}$ and the different substrate temperatures: $T_{s}=200{ }^{\circ} \mathrm{C}(\mathrm{a}, \mathrm{b}) ; T_{s}=350{ }^{\circ} \mathrm{C}(\mathrm{c}, \mathrm{d}) ; T_{s}=500{ }^{\circ} \mathrm{C}(\mathrm{e}, \mathrm{f})$

a

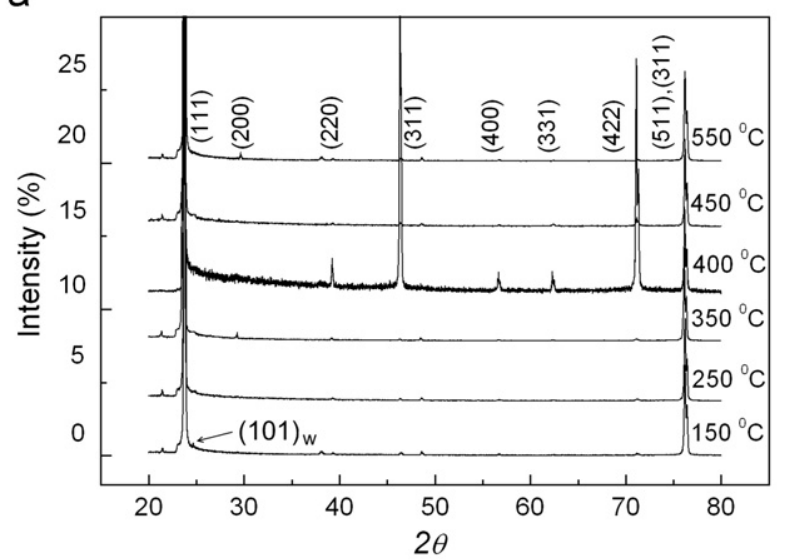

b

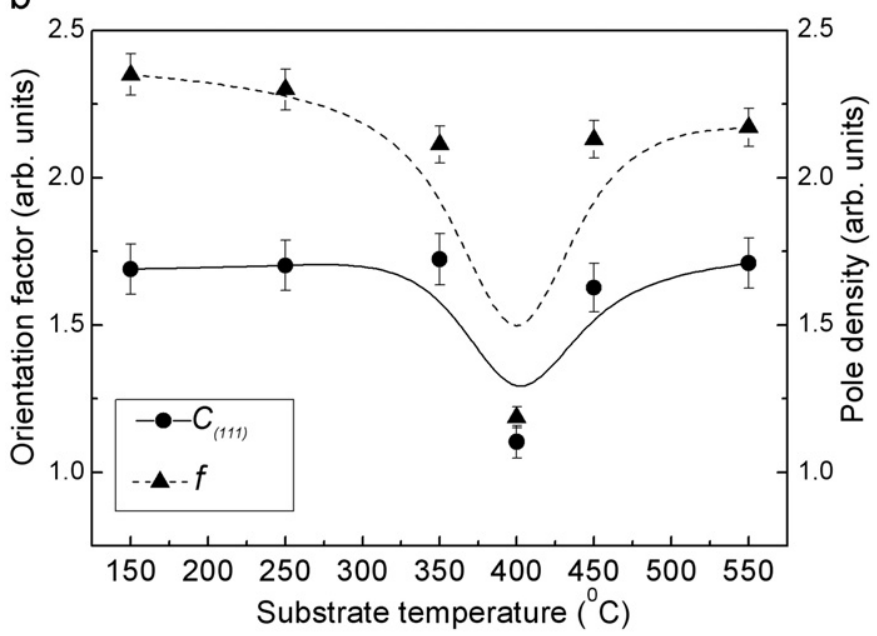

Fig. 3. X-ray patterns of CdTe films deposited at the different $T_{S}(\mathrm{a})$. Pole density $\left(C_{1} 111\right)-\bullet$ and orientation factor $(f)-\mathbf{\Lambda}$ as function of substrate temperature (b).

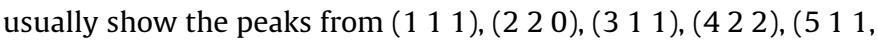
$333)$ planes of the cubic phase. It indicates that the films obtained at $T_{s} \geq 250{ }^{\circ} \mathrm{C}$ correspond to single cubic phase only.
For the films grown at $T_{s}=150{ }^{\circ} \mathrm{C}$ the X-ray peak from $\left(\begin{array}{lll}1 & 0 & 1\end{array}\right)$ plane at $2 \theta=(24.8-25.2)^{\circ}$ with intensity less than $1 \%$ was observed. This peak corresponds to the trace ( $2-3 \%$ concentration) of the metastable wurtzite phase.

As a rule, the reflection peak from the (1 111 ) plane which corresponds to the [ 1111 ] growth texture has the most intensity. The results of the pole density $\left(C_{1} 11\right)$ calculations indicate that the value of $C_{(111)} \sim 1.7$ and weakly depends on $T_{s}$ (Fig. $3 \mathrm{~b}$ ). However, the texture of the films at $T_{s}=400^{\circ} \mathrm{C}$ is somewhat reduced. It should be noted that at this substrate temperature the minimum of orientation factor $f$ was also observed (Fig. 3b). Early analogous results were obtained in [8], but the minimum of $C_{(111)}$ was observed at lower substrate temperature, namely at $T_{s}=330-350{ }^{\circ} \mathrm{C}$. This can be explained by the change in the film growth mechanism at this substrate temperature.

In most cases, the determination of the substructural characteristics $L$ and $\varepsilon$ based on the measurements of the broadening of ( $\left.\begin{array}{lll}1 & 1 & 1\end{array}\right)-\left(\begin{array}{lll}2 & 2 & 2\end{array}\right)$ diffraction peaks which correspond to a cubic phase. Whereas, low intensity of the diffraction peaks from $\left(\begin{array}{lll}2 & 0 & 0\end{array}\right)$ to $(400)$ plane allowed us to determine these characteristics as well as the SF defect concentrations $\alpha$ only for two samples, namely: deposited at $T_{s}=350$ and $550^{\circ} \mathrm{C}$. The structural and substructural parameters of the investigated CdTe films are presented in Table 1.

The dependences of the $L$ and $\varepsilon$ values on the substrate temperature for the direction orthogonal to $\left(\begin{array}{lll}1 & 1 & 1\end{array}\right)$ crystal plane are shown in Fig. 4. The obtained data indicate good correlations between the results obtained by different approximation methods [22-25].

As can be seen from Fig. 4a, the CSD size increases from $L \sim 60-65$ to $L \sim 85-100 \mathrm{~nm}$ when the substrate temperature increases and then decreases to $L \sim 55-58 \mathrm{~nm}$. These results allowed us to determine the optimal temperature range $\left(T_{s}=325-400{ }^{\circ} \mathrm{C}\right)$ which corresponds to the maximal CSD size. The calculated values of CSD size are similar to the data obtained in [10] $(L=39-81 \mathrm{~nm})$ and in [5] $(L=22-78 \mathrm{~nm})$ for the thin films obtained by thermal vacuum evaporation. However in $[5,10]$ the calculation was carried out by using the Sherrer equations, which do not take into account the presence of microdeformation in the films. Therefore these results are overestimated. Whereas the maximum value of CSD size $(L \sim 86 \mathrm{~nm}$, approximation by three-fold convolution) was obtained in this work. The 
Table 1

Structural and substructural parameters of CdTe films.

\begin{tabular}{|c|c|c|c|c|c|c|c|c|c|}
\hline$T_{s}\left({ }^{\circ} \mathrm{C}\right)$ & $l(\mu \mathrm{m})$ & $d(\mu \mathrm{m})$ & $(h k l)$ & $L(\mathrm{~nm})$ & $\varepsilon \times 10^{3}$ & $\sigma(\mathrm{MPa})$ & $\rho_{V} \times 10^{14}\left(\operatorname{lin} / \mathrm{m}^{2}\right)$ & $\rho_{T} \times 10^{14}\left(\mathrm{lin} / \mathrm{m}^{2}\right)$ & $\alpha(\%)$ \\
\hline \multirow[t]{2}{*}{150} & 18 & $\leq 1$ & $\left(\begin{array}{lll}1 & 1 & 1\end{array}\right)-\left(\begin{array}{lll}2 & 2 & 2\end{array}\right)$ & 61.02 & 1.07 & 43.9 & 1.48 & 1.72 & - \\
\hline & & & $\left(\begin{array}{lll}2 & 0 & 0\end{array}\right)-\left(\begin{array}{lll}4 & 0 & 0\end{array}\right)$ & - & - & - & - & - & \\
\hline \multirow[t]{2}{*}{250} & 18 & 1.5 & $\left(\begin{array}{lll}1 & 1 & 1\end{array}\right)-\left(\begin{array}{lll}2 & 2 & 2\end{array}\right)$ & 64.88 & 0.59 & 24.2 & 0.45 & 0.89 & - \\
\hline & & & $\left(\begin{array}{lll}2 & 0 & 0\end{array}\right)-\left(\begin{array}{lll}4 & 0 & 0\end{array}\right)$ & - & - & - & - & - & \\
\hline \multirow[t]{2}{*}{350} & 18 & 4 & $\left(\begin{array}{lll}1 & 1 & 1\end{array}\right)-\left(\begin{array}{lll}2 & 2 & 2\end{array}\right)$ & 86.66 & 0.70 & 28.6 & 0.63 & 0.74 & 0.19 \\
\hline & & & $\left(\begin{array}{lll}2 & 0 & 0\end{array}\right)-\left(\begin{array}{lll}4 & 0 & 0\end{array}\right)$ & 101.16 & 0.40 & 16.2 & 0.17 & 0.35 & \\
\hline \multirow[t]{2}{*}{400} & 16 & 7 & $\left(\begin{array}{lll}1 & 1 & 1\end{array}\right)-\left(\begin{array}{lll}2 & 2 & 2\end{array}\right)$ & 75.32 & 0.71 & 28.9 & 0.64 & 0.92 & - \\
\hline & & & $\left(\begin{array}{lll}2 & 0 & 0\end{array}\right)-\left(\begin{array}{lll}4 & 0 & 0\end{array}\right)$ & - & - & - & - & - & \\
\hline \multirow[t]{2}{*}{450} & 14 & 10 & $\left(\begin{array}{lll}1 & 1 & 1\end{array}\right)-\left(\begin{array}{lll}2 & 2 & 2\end{array}\right)$ & 72.87 & 0.73 & 29.9 & 0.68 & 0.98 & - \\
\hline & & & $\left(\begin{array}{lll}2 & 0 & 0\end{array}\right)-\left(\begin{array}{lll}4 & 0 & 0\end{array}\right)$ & - & - & - & - & - & \\
\hline \multirow[t]{2}{*}{550} & 14 & 13 & $\left(\begin{array}{lll}1 & 1 & 1\end{array}\right)-\left(\begin{array}{lll}2 & 2 & 2\end{array}\right)$ & 56.94 & 0.65 & 26.6 & 0.54 & 1.12 & 0.79 \\
\hline & & & $\left(\begin{array}{lll}2 & 0 & 0\end{array}\right)-\left(\begin{array}{lll}4 & 0 & 0\end{array}\right)$ & 94.22 & 0.21 & 8.7 & 0.19 & 0.40 & \\
\hline
\end{tabular}

a

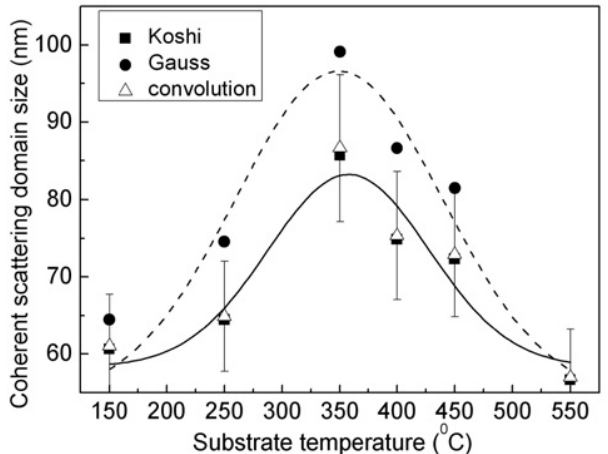

b

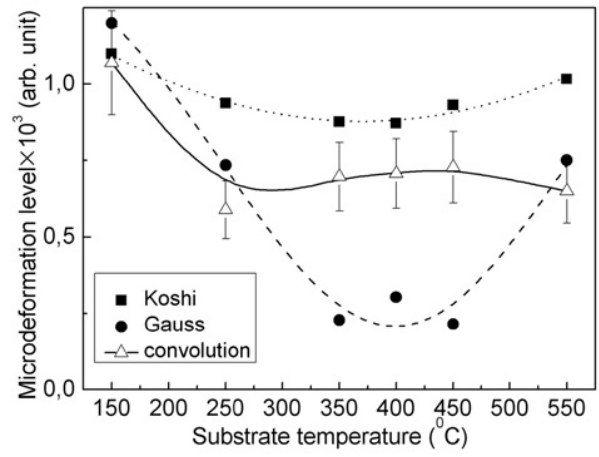

Fig. 4. Dependence of CSD size $L$ (a) and microdeformation level $\varepsilon$ (b) on the substrate temperature for the different approximations.

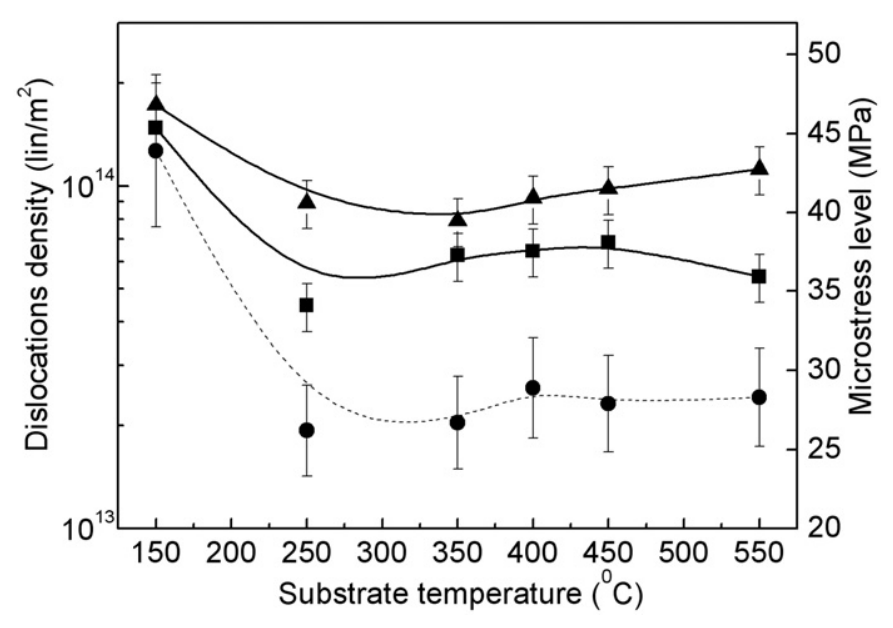

Fig. 5. The microstress level $\sigma-\bullet$, and dislocations density $\rho$ as function of the substrate temperature $T_{s}$ : $\mathbf{\square}$-in CSD volume $\left(\rho_{V}\right), \boldsymbol{\Delta}$-total dislocations density $\left(\rho_{T}\right)$.

microdeformation level weakly decrease from $\varepsilon=(1.1-1.2) \times 10^{-3}$ to $(0.7-0.8) \times 10^{-3}$ in the substrate temperature region from 150 to $550{ }^{\circ} \mathrm{C}$ (Fig. $4 \mathrm{~b}$ ).

The microdeformation level in the CdTe films (Fig. 5) was calculated by using the Yung modulus value $E=41 \mathrm{GPa}$ [8]. It was found that the value $\varepsilon$ varies in the range of $\sigma=26-44 \mathrm{MPa}$. The maximal values of microstress levels $\sigma=44 \mathrm{MPa}$ are 2-4 times less than the value obtained in [5] ( $\sigma=82-164 \mathrm{MPa})$ for films deposited by thermal evaporation method. Fig. 5 shows the results of calculating the dislocation density in the investigated films. The value of total dislocation density $\rho_{T}$ is in the range from $0.74 \times 10^{14}$ to $1.72 \times 10^{14} \mathrm{lin} / \mathrm{m}^{2}$. The dislocation density in CSD volume $\rho_{V}$ is in the range from $0.54 \times 10^{14}$ to $1.48 \times 10^{14} \mathrm{lin} / \mathrm{m}^{2}$. It should be noted that the calculated total dislocations density $\rho_{T}$ was less than values $(0.65-6.62) \times 10^{14} \mathrm{lin} / \mathrm{m}^{2}$ obtained in [10].

It should be noted that unlike $[5,10]$ in our work the investigation of substructural properties of CdTe thin films was carried out for the wide range of growth conditions which are determined by the substrate temperature.

In Fig. 6 the photoluminescence spectra of the CdTe polycrystalline films at $4.5 \mathrm{~K}$ for the samples obtained at the different substrate temperatures $T_{s}$ are shown. An analysis of the observed photoluminescence spectra (Fig. 6) reveals a broad band in the long-wavelength region 770-900 nm (1.38-1.61 eV) which is caused both by the recombination of the donor-acceptor pairs with the participation of the acceptor $\left(\mathrm{V}_{\mathrm{Cd}^{-}}^{-}+D^{+}\right)^{-}$-complexes and the presence of the $1.47 \mathrm{eV}$ emission band caused by extended defects like dislocations [14-16]. Therefore, the photoluminescence intensity in this spectral range can be used as a measure to evaluate the relative dislocation density. It should be noted that the acceptor complex includes a doubly charged cadmium vacancy $\left(\mathrm{V}_{\mathrm{Cd}}^{2^{-}}\right)$and a singly ionized donor $\left(\mathrm{D}^{+}\right)$. The ionized donors can be the residual impurities of group III atoms (first of all atoms of In) positioned at cationic sites. According to [28] these impurity atoms are also present in pure CdTe.

As it can be seen from Fig. 6, the most intensity of the broad band corresponds to the films obtained at $T_{s}=250^{\circ} \mathrm{C}$. In the case of the films obtained at $T_{s}=350{ }^{\circ} \mathrm{C}$ the intensity of broad band is insignificant. Therefore for CdTe films obtained at such growth condition the dislocation density is small. This result is in accordance with the data presented in Fig. 5, where the minimum of the total dislocations density in CdTe films corresponds to the substrate temperature $T_{s}=350{ }^{\circ} \mathrm{C}$. It should be noted that the dislocations are situated, in main, in the volume of the CSD since in Fig. 5 the minimum of such type dislocations also is at the same 


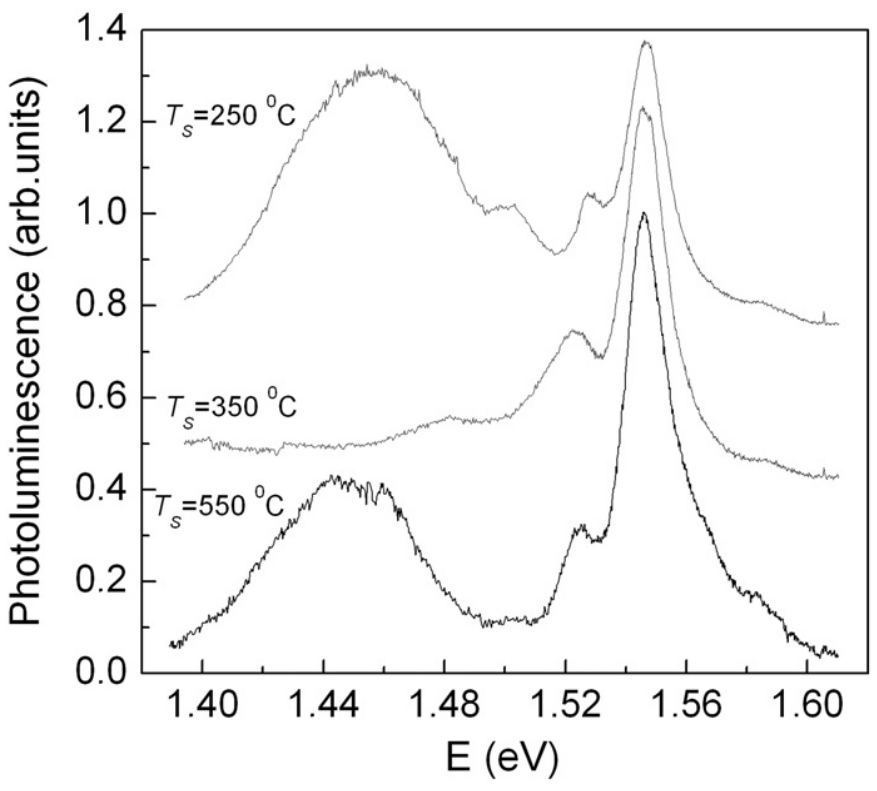

Fig. 6. The photoluminescence spectra of the CdTe polycrystalline films at $4.5 \mathrm{~K}$ for the samples obtained at the different substrate temperatures $T_{s}$.

temperature. As can be seen from Fig. 6, the intensity of broad photoluminescence band of the CdTe films with $T_{s}=550{ }^{\circ} \mathrm{C}$ is considerable. Therefore, the dislocation density for these films is larger than in the case of films with $T_{s}=350{ }^{\circ} \mathrm{C}$. In addition, the concentrations of SF in thin films obtained at $T_{s}=550{ }^{\circ} \mathrm{C}$ is four times more than for the CdTe films with $T_{s}=350{ }^{\circ} \mathrm{C}$. At the same time the crystallite sizes for the films obtained at 350 and $550{ }^{\circ} \mathrm{C}$ correspond to 4 and $13 \mu \mathrm{m}$, respectively.

The most intense line in the photoluminescence spectra of CdTe films is observed at $1.545 \mathrm{eV}$. It indicates that this line can be caused by the emission with participation of free electrons and the shallow acceptor level with the energy about $60 \mathrm{meV}$, since the band gap energy of CdTe at $4.5 \mathrm{~K}$ is $1.606 \mathrm{eV}$. In this case the recombination of free electrons with the acceptor holes occurs. According to Molva et al. [29] this acceptor level may be caused by the presence of $\mathrm{Na}$ or Li residual impurities in CdTe films. This impurity atoms are the typical residual impurities in II-VI compounds [28]. The low intensity lines observed on the longwavelength wing of the most intense line correspond to the 1LOand 2LO-phonon replicas of this line. At the same time, the line at $1.545 \mathrm{eV}$ may be caused by the recombination of the donor electrons with the energy $E_{c}-0.010 \mathrm{eV}$ and the acceptor holes with $E_{v}+0.050 \mathrm{eV}$. In this case the acceptor level corresponds to the single charged cadmium vacancies [30-33].

As it can be seen from Fig. 6, the low intensity line is observed on the short-wavelength wing of the intense line. The appearance of this line is caused by the recombination of acceptor bound excitons, i.e. corresponds to the $A^{0} X$-line $[29,30]$. The fact that we are able to observe the excitonic line in the photoluminescence spectra indicates that the CdTe polycrystalline films are of good optical quality. The presence of the $\mathrm{A}^{0} \mathrm{X}$-line in the photoluminescence spectra of the CdTe films indicates that these films are p-type and the concentration of the donor centers in the investigated films is insignificant.

\section{Conclusions}

In this work we studied the effect of condensation temperature on structural, substructural and photoluminescence properties of
CdTe polycrystalline thin films obtained by CSVS technique for the first time. It was shown that increase of the substrate temperature $T_{s}$ from 150 to $550{ }^{\circ} \mathrm{C}$ leads to the changing of the film growth mechanism. The films are highly dispersed at $T_{s} \leq 200{ }^{\circ} \mathrm{C}$ and for higher temperatures they have a columnar-like structure with clear growth texture and the average grain size up to $13 \mu \mathrm{m}$. As a result of these investigations the optimal temperature conditions $\left(T_{e}=620^{\circ} \mathrm{C}, T_{s}=350{ }^{\circ} \mathrm{C}\right)$ of the growth of polycrystalline $\mathrm{CdTe}$ films which have a single cubic phase with the low dislocation density and of SF defect concentration were determined.

\section{Acknowledgements}

This research was supported by the Ministry of Education and Science of Ukraine (Grant no. 0110U001151: "CdTe and CdTebased solid-solutions thin films for solar cells and radiation detectors").

\section{References}

[1] J. Poortmans, V. Arkhipov, in: Thin Film Solar Cells: Fabrication, Characterization and Application, John Wiley \& Sons, Chichester, 2006, p. 471.

[2] A. Bosio, N. Romeo, S. Mazzamuto, V. Canevari, Prog. Cryst. Growth Charact. Mater. 52 (2006) 247.

[3] X. Wu, Sol. Energy 6 (2004) 803.

[4] R.W. Birkmire, E. Eser, Annu. Rev. Mater. Sci. 27 (1997) 625.

[5] A.A. Ramadan, A.A. Mongy, I.S. Ahmed Farag, A.M. El-Shabiny, F.A. Radwan, H.I. Ismail, H.M. Hashem, Thin Solid Films 423 (2003) 146

[6] P.A. Panchekha, Functional Mater. 7 (2000) 1.

[7] K. Zanio, Semiconductors and semimetals, Cadmium Telluride, Academic Press, New York, 1978, p. 196.

[8] J. Luschitz, B. Siepchen, J. Schaffner, K. Lakus-Wollny, G. Haindl, A. Klein, W. Jaegermann, Thin Solid Films 517 (2009) 2125

[9] J.H. Lee, D.G. Lim, J.S. Yi, Sol. Energy Mat. Sol. Cells 75 (2003) 235

[10] S. Lalitha, R. Sathyamoorthy, S. Senthilarasu, A. Subbarayan, K. Natarajan, Sol. Energy Mat. Sol. Cells 82 (2004) 187.

[11] Yu.P. Gnatenko, P.M. Bukivskij, Yu.P. Piryatinski, I.O. Faryna, O.A. Shigiltchoff, R.V. Gamernyk, Appl. Phys. Lett. 95 (2009) 112.

[12] Yu.P. Gnatenko, M.S. Brodyn, I.O. Faryna, P.M. Bukivskij, O.A. Shigiltchoff, M.S. Furyer, R.V. Gamernyk, N. Kukhtarev, T. Kukhtareva, Phys. Status Solidi (a) 204 (2007) 2431.

[13] J. Aguilar-Hernandez, M. Cardenas-Garcia, G. Contreras-Puente, J. VidalLarramendi, Mater. Sci. Eng. B102 (2003) 203.

[14] T. Okamoto, A. Yamada, M. Konagai, Thin Solid Films 387 (2001).

[15] V.V. Ushakov, Yu.V. Klevkov, Semiconductors 41 (2007) 140.

[16] N.I. Tarbaev, G.A. Shepel'skii, Semiconductors 40 (2006) 1175

[17] N. Abbas Shah, A. Ali, Z. Ali, A. Maqsood, A.K.S. Aqili, J. Crystal Growth 284 (2005) 477

[18] A. Ali, N. Abbas Shah, A. Maqsood, J. Cryst. Growth 311 (2009) 2367.

[19] Q. Jiang, B.J. Cantwell, J.T. Mullins, A. Basu, A.W. Brinkman, J. Cryst. Growth 310 (2008) 1664

[20] V.V. Kosyak, M.M. Kolesnik, A.S. Opanasyuk, J. Mater. Sci.: Mater. Electron. 19 (2008) S375.

[21] JCPDS, International Centre for Diffraction Data, USA, Card Number 75-2086.

[22] B.E. Warren, in: X-ray Diffraction, Dover, Mineola, 1990, p. 251.

[23] D.K. Bowen, K.B. Tanner, X-Ray Metrology in Semiconductor Manufacturing Taylor \& Francis Group p. 251.

[24] S.N. Danilchenko, O.G. Kukharenko, C. Moseke, I.Y.u Protsenko, L.F. Sukhodub B. Sulkio-Cleff, Cryst. Res. Technol. 37 (2002) 1234.

[25] D. Kurbatov, H. Khlyap, A. Opanasyuk, Phys. Status Solidi (a) 206 (2009) 1549.

[26] D. Kurbatov, V. Kosyak, M. Kolesnyk, A. Opanasyuk, S. Danilchenko, Integrated Ferroelectrics 103 (2009) 32.

[27] T. Mahalingam, V.S. John, G. Ravi, P.J. Sebastian, Cryst. Res. Technol. 37 (2002) 329.

[28] R. Soundararajan, K.G. Lynn, S. Awadallah, C. Szeles, Su-Huai Wei, J. Electr. Mater. 35 (2006) 1333.

[29] E. Molva, J. Pauttrat, K. Seminadayar, G. Milchberg, N. Magnea, Phys. Rev. B 30 (1984) 3344.

[30] Yu.P. Gnatenko, Appl. Phys. 94 (2003) 4896.

[31] Yu.P. Gnatenko, R.V. Gamernyk, I.O. Farina, P.I. Babii, Sov. Phys. Solid State 40 (1998) 1107

[32] Yu.P. Gnatenko, I.O. Faryna, P.M. Bukivskij, O.A. Shigiltchoff, R.V. Gamernyk, S.Y. Paranchych, L.D. Paranchych, J. Phys.: Condens. Matter 14 (2002) 7027.

[33] Yu.P. Gnatenko, Yu.P. Piryatinski, P.M. Bukivskij, D.D. Kolendryckyj, O.A Shigiltchoff, R.V. Gamernyk, J. Phys.: Condens. Matter 18 (2006) 9603. 